\title{
An alternative model for the earliest evolution of vascular plants
}

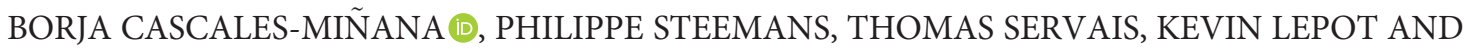 \\ PHILIPPE GERRIENNE
}

LETHAIA

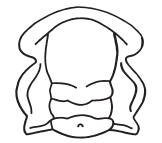

\begin{abstract}
Cascales-Miñana, B., Steemans, P., Servais, T., Lepot, K., \& Gerrienne, P. 2019: An alternative model for the earliest evolution of vascular plants. Lethaia, Vol. 52, pp. 445-453.

Land plants comprise the bryophytes and the polysporangiophytes. All extant polysporangiophytes are vascular plants (tracheophytes), but to date, some basalmost polysporangiophytes (also called protracheophytes) are considered non-vascular. Protracheophytes include the Horneophytopsida and Aglaophyton/Teruelia. They are most generally considered phylogenetically intermediate between bryophytes and vascular plants and are therefore essential to elucidate the origins of current vascular floras. Here, we propose an alternative evolutionary framework for the earliest tracheophytes. The supporting evidence comes from the study of the Rhynie chert historical slides from the Natural History Museum of Lille (France). From this, we emphasize that Horneophyton has a particular type of tracheid characterized by narrow, irregular, annular and/or, possibly spiral wall thickenings of putative secondary origin, and hence that it cannot be considered non-vascular anymore. Accordingly, our phylogenetic analysis resolves Horneophyton and allies (i.e. Horneophytopsida) within tracheophytes, but as sister to eutracheophytes (i.e. extant vascular plants). Together, horneophytes and eutracheophytes form a new clade called herein supereutracheophytes. The thin, irregular, annular to helical thickenings of Horneophyton clearly point to a sequential acquisition of the characters of water-conducting cells. Because of their simple conducting cells and morphology, the horneophytophytes may be seen as the precursors of all extant vascular plant biodiversity. $\square$ Cladistics, Horneophyton, lower Devonian, Rhynie chert, tracheophyte.
\end{abstract}

\begin{abstract}
Borja Cascales-Miñana凶 [borja.cascales-minana@univ-lille.fr], and Thomas Servais [thomas.servais@univ-lille.fr], CNRS, UMR 8198 - Evo-Eco-Paleo, University of Lille, F-59000 Lille, France; Philippe Steemans [p.steemans@uliege.be], Philippe Gerrienne [p.gerrienne@uliege.be],EDDy lab/Palaeobotany and Palaeopalynology, UR Geology, University of Liege, Quartier Agora, Allée du 6 Août, 14, Bât. B18 B-4000 Liège 1, Belgium; Kevin Lepot [kevin.lepot@univ-lille.fr], CNRS, UMR 8187, Laboratoire d'Océanologie et de Géosciences, Université Littoral Côte d'Opale, Université de Lille, 59000 Lille, France; manuscript received on 10/09/2018; manuscript accepted on 15/12/ 2018.
\end{abstract}

Documenting the greening of the earliest land ecosystems requires a full understanding of the major steps in plant evolution, most particularly the origin of vascular land plants. Land plants (embryophytes) comprise the bryophytes (i.e. plant with parasitic unbranched sporophyte and a single sporangium) and polysporangiophytes (i.e. plants with independent branched sporophyte and multiple sporangia; Kenrick \& Crane 1997; Kenrick 2000). All living polysporangiophytes are vascular plants (tracheophytes), but the basal-most representatives of the clade are considered non-vascular (Kenrick 2000) and structurally intermediate between bryophytes and vascular plants. Those non-vascular polysporangiophytes, also called protracheophytes, include the Horneophytopsida (Caia, Horneophyton and Tortilicaulis) and Aglaophyton/Teruelia (Cascales-Miñana \& Gerrienne 2017; and references therein). Most of them are known in great detail because they come from the Early Devonian (mid-Pragian-?earliest Emsian, Wellman 2006) Rhynie Lagerstätte, Aberdeenshire, in Scotland (see Kidston \& Lang 1917, 1920a,b; Edwards et al. 2017), where the preservation of the fossils is exquisite. The earliest preserved terrestrial ecosystem of Rhynie was indeed formed in a hot-spring environment (Channing 2017; Edwards et al. 2017), which results in a unique and exceptional anatomical preservation of the early land plants, among other organisms. Consequently, four Rhynie chert plants (Aglaophyton, Horneophyton, Rhynia and Asteroxylon), showing different grades of complexity of water-conducting cells, occupy key steps in current plant phylogeny (Kenrick 2000; Ligrone et al. 2012). Those plants are essential to elucidate the origin of vascular plant biodiversity, especially Horneophyton lignieri (Kidston \& Lang) Barghoorn \& Darrah, currently 
belonging to the earliest lineage of polysporangiophytes.

Horneophyton is one of the historical plants firstly described by Kidson and Lang from the Rhynie chert (Kidston \& Lang 1920a; Barghoorn \& Darrah 1938). Morphologically, Horneophyton is a small leafless free-sporing plant characterized by bulbous rhizomes, erect dichotomous axes and terminal sporangia with a central columella (Kidston \& Lang 1920a; Kenrick \& Crane 1997). After Kidson \& Lang's original diagnosis, several researchers have focused attention on this plant, generating a wide literature. For instance, there is well-documented evidence of the anatomy of aerial axes and rhizomes (Edwards 2004; Kerp 2017), of the structure of sporangia (Eggert 1974; El-Saadawy \& Lacey 1979), as well as of the in situ spores (Wellman et al. 2004; Wellman 2017). Even the gametophyte, Langiophyton mackiei, is well known (Kerp 2017). However, the phylogenetic position of Horneophyton is controversial. Horneophyton presents a mixture of characters typical of tracheophytes (e.g. branched sporophyte, well-developed cuticles with stomata on axes; Kidston \& Lang 1920a; Kerp 2017), but by still retaining some bryophyte features (e.g. columellate sporangium; Kidston \& Lang 1920a; Eggert 1974). Recent observations on the basal part of the upright axes further show the presence of water-conducting cells with annular to slightly helical thickenings (Kerp 2017), which obviously calls into question the non-vascular nature of Horneophyton. This paper aims to address this issue and its evolutionary implications.

\section{Material and methods}

We studied for the first time the series of petrographic thin sections from the historical W. Hemingway slides of the Natural History Museum of Lille, which belong to the same Rhynie chert collection as those originally studied by Kidston \& Lang (1917, 1920a,b). Concretely, we studied 30 glass slides $(8 \times$ Aglaophyton, $8 \times$ Rhynia, 9× Hor neophyton and $5 \times$ Asteroxylon; see Table 1) showing typical exquisitely well-preserved reproductive and vegetative structures of the Rhynie flora. Photographs were taken using a Nikon Df camera coupled to a Zeiss Stemi 2000-C stereomicroscope and with a Zeiss Axioskop microscope coupled to a Zeiss Axiocam camera.

The phylogenetic position of Horneophyton was assessed via PAUP* 4.0 (Phylogenetic Analysis
Table 1. List of slides of the Hemingway historical collection of the Rhynie chert housed at the Natural History Museum of Lille used in this study. For each slide, it is specified both the original and given code as well as the considered plant diversity.

\begin{tabular}{|c|c|c|c|}
\hline Slide & Hemingway code & Museum code & Rhynie flora \\
\hline 1 & $360-107$ & MGLame-1 & Aglaophyton \\
\hline 2 & $405-44$ & MGLame-2 & Aglaophyton \\
\hline 3 & $405-5$ & MGLame-3 & Aglaophyton \\
\hline 4 & $405-7$ & MGLame-4 & Aglaophyton \\
\hline 5 & 459 & MGLame-5 & Aglaophyton \\
\hline 6 & $459-51$ & MGLame-6 & Aglaophyton \\
\hline 7 & $459-52$ & MGLame-7 & Aglaophyton \\
\hline 8 & $459-53$ & MGLame-8 & Aglaophyton \\
\hline 9 & $369-37$ & MGLame-9 & Rhynia \\
\hline 10 & $363-37$ & MGLame-10 & Rhynia \\
\hline 11 & $363-40$ & MGLame-11 & Rhynia \\
\hline 12 & $369-24$ & MGLame-12 & Rhynia \\
\hline 13 & $377-12$ & MGLame-13 & Rhynia \\
\hline 14 & $377-6$ & MGLame-14 & Rhynia \\
\hline 15 & $470-75$ & MGLame-15 & Rhynia \\
\hline 16 & 686 & MGLame-16 & Rhynia \\
\hline 17 & $357-61$ & MGLame-17 & Horneophyton \\
\hline 18 & $359-2$ & MGLame-18 & Horneophyton \\
\hline 19 & $359-5$ & MGLame-19 & Horneophyton \\
\hline 20 & $359-6$ & MGLame-20 & Horneophyton \\
\hline 21 & $379-29$ & MGLame-21 & Horneophyton \\
\hline 22 & 379-31 & MGLame-22 & Horneophyton \\
\hline 23 & 379-34 & MGLame-23 & Horneophyton \\
\hline 24 & $439-63$ & MGLame-24 & Horneophyton \\
\hline 25 & $439-65$ & MGLame-25 & Horneophyton \\
\hline 26 & $355-26$ & MGLame-26 & Asteroxylon \\
\hline 27 & $366-98$ & MGLame-27 & Asteroxylon \\
\hline 28 & $368-29$ & MGLame-28 & Asteroxylon \\
\hline 29 & $426-10$ & MGLame-29 & Asteroxylon \\
\hline 30 & $439-31$ & MGLame-30 & Asteroxylon \\
\hline
\end{tabular}

Using Parsimony, and other Methods, http://pa up.phylosolutions.com/). We codified a character matrix (Data S1) including 21 core taxa of earliest land plants (Kenrick \& Crane 1997; Kenrick 2000). Data matrix was prepared on 32 morphological and anatomical characters (Table S1). List of characters (and character states) was adapted from Kenrick \& Crane (1997) and CascalesMiñana \& Gerrienne (2017), with some modifications (Table S1). Bryophytes were transferred to outgroup and treated as monophyletic according to Puttick et al.'s (2018) recent maximum-likelihood and Bayesian estimations. See Appendix S1 for implementation. The topology of resulted consensus tree (consistency index $=0.875$; homoplasy index $=0.125$; retention index $=0.9213$, rescaled consistency index $=0.8062 ; \quad$ Appendix S2) was plotted against stratigraphy using strap (Stratigraphic Tree Analysis for Palaeontology; Bell \& Lloyd 2104). The calibration of polysporangiophyte splits is based on to the temporal distribution of the considered fossil plants (Appendix S3). Strap analysis was performed according to Bell \& Lloyd's (2014) tutorial. 


\section{Results and discussion}

The observed diversity in the water-conducting cells of the four Rhynie chert plant studied here is shown in Figure 1. In Aglaophyton (Fig. 1A, E, I, M, N), the water-conducting cells are characterized by the presence of chains and clusters of interconnected bubblelike structures in their lumen (Edwards 1986, 2004). Whether those bubbles are of primary or secondary origin is unknown, but previous studies have shown that they were most probably unlignified (Boyce et al. 2003). The conducting cells of Rhynia (Fig. 1B, F, J, O, P) are of the S-type as defined by Kenrick \& Crane (1991). S-type conducting cells are elongate cells with large annular to helical thickenings including a spongy interior covered towards the lumen by a thin decay-resistant microporate layer (Kenrick \& Crane 1991, 1997), considered unlignified by Boyce et al. (2003). The conducting cells of Horneophyton (Figs. 1C, G, K, Q, R, 2) include thin irregular, annular to helical thickenings. Those thickenings are of unknown origin and nature, but their dark colour is suggestive of the presence of a decay-resistant component that may have locally allowed the preservation of abundant organic matter. The tracheids of Asteroxylon (Fig. 1D, H, L, S, T) are of the G-type as defined by Kenrick \& Crane (1991). They show annular to helical thickenings with pores distributed between the thickenings. Boyce et al. (2003) have shown that Asteroxylon tracheids are most probably heavily lignified.

Two important observations are derived from the water-conducting cells diversity illustrated in Figure 1. Firstly, the Aglaophyton and Rhynia conducting strands (Fig. 1A, E, B, F) are more closely similar to each other than to those of Horneophyton and Asteroxylon, which show thicker cell walls in cross-sections (Figs. 1C, D, G, H, 2). Secondly, the complexity of the conducting cells obviously increases from Aglaophyton, where there is an apparent lack of tracheid thickenings (Fig. 1I, M, N), to Asteroxylon, which shows well-defined annular secondary thickenings (Fig. 1L, S, T). Most importantly, we note that Horneophyton presents a genuine type of conducting cells characterized by irregular, annular and/or, possibly spiral wall thickenings (Fig. 1K, $\mathrm{R}, \mathrm{S}$ ) of putative secondary origin. Accordingly, our phylogenetic analysis resolves Horneophyton and allies within tracheophytes, but interestingly, not as the basalmost lineage but as a sister clade to eutracheophytes (Fig. 3). The two plant groups constitute a new clade that we call herein supereutracheophytes. This clade is characterized by narrow, irregular, annular and/or, possibly spiral wall thickenings of putative secondary origin, while eutracheophytes present a clear thick, lignified wall layer. Figure 3 further shows that Horneophyton and allies are more derived than the paratracheophytes (=Rhyniaceae), while Aglaophyton is resolved as the earliest diverging polysporangiophyte, and the single lineage between the bryophytes and the vascular plants.

In 1920, Kidston \& Lang (1920a) referred to Horneophyton (formerly Hornea) as 'another vascular plant from the Rhynie peat-bed' and documented cells with distinct narrow thickenings forming irregularly connected rings or a spiral (Kidston \& Lang 1920a, figs. 52-53). Indeed, the Hornea original diagnosis describes the vascular strand as follows: 'stele of stem with a zone of phloem surrounding the xylem composed of small central and wider peripheral tracheids' (Kidston \& Lang 1920a). The same description appears in Barghoorn \& Darrah's (1938) Horneophyton diagnosis. More recently, Edwards (2004) pointed out that the Horneophyton terete strands 'show unequivocal narrow interconnected annular or spiral thickenings, with the smaller elements situated centrally', and further added 'the tracheids were surrounded by elongate, thin-walled cells interpreted as phloem'. Likewise, Kerp (2017) has recently illustrated the presence of 'water-conducting cells with annular to slightly helical wall thickenings in the basal part of the upright axis' for Horneophyton. Our observations also show annular and/or spiral wall thickenings in Horneophyton conducting cells (Fig. 1Q, R). This is consistent with the original diagnosis (Kidston \& Lang 1920a; Barghoorn \& Darrah 1938) and with the subsequent descriptions and the current interpretations (Edwards 2004; Kerp 2017), which provides strong support for Horneophyton being a vascular plant.

Fundamental characters supporting a close relationship between Horneophyton and eutracheophytes are: (1) the decay resistance of the conducting cell wall; and (2) thickenings of cell wall (characters 16 and 17 from Table S1, respectively). Decay resistance is a character linked to the presence of lignin in the secondary wall of the conducting cell, which accounts for an increased thickness of the wall (Kenrick \& Edwards 1988). Unthickened water-conducting cells are typical of mosses (Roberts et al. 2012). They can be also observed in Aglaophyton (Fig. 1E, I). The wall of the conducting cells of the paratracheophytes presents a thin decay-resistant layer facing the lumen (Kenrick \& Crane 1991; Kenrick et al. 1991a,b), but it is unclear whether the decay-resistant layer is of the secondary nature and whether it includes lignin. Recent evidence, however, suggests that the development of the wall thickenings in Rhynia occurs shortly after elongation and hence that it 


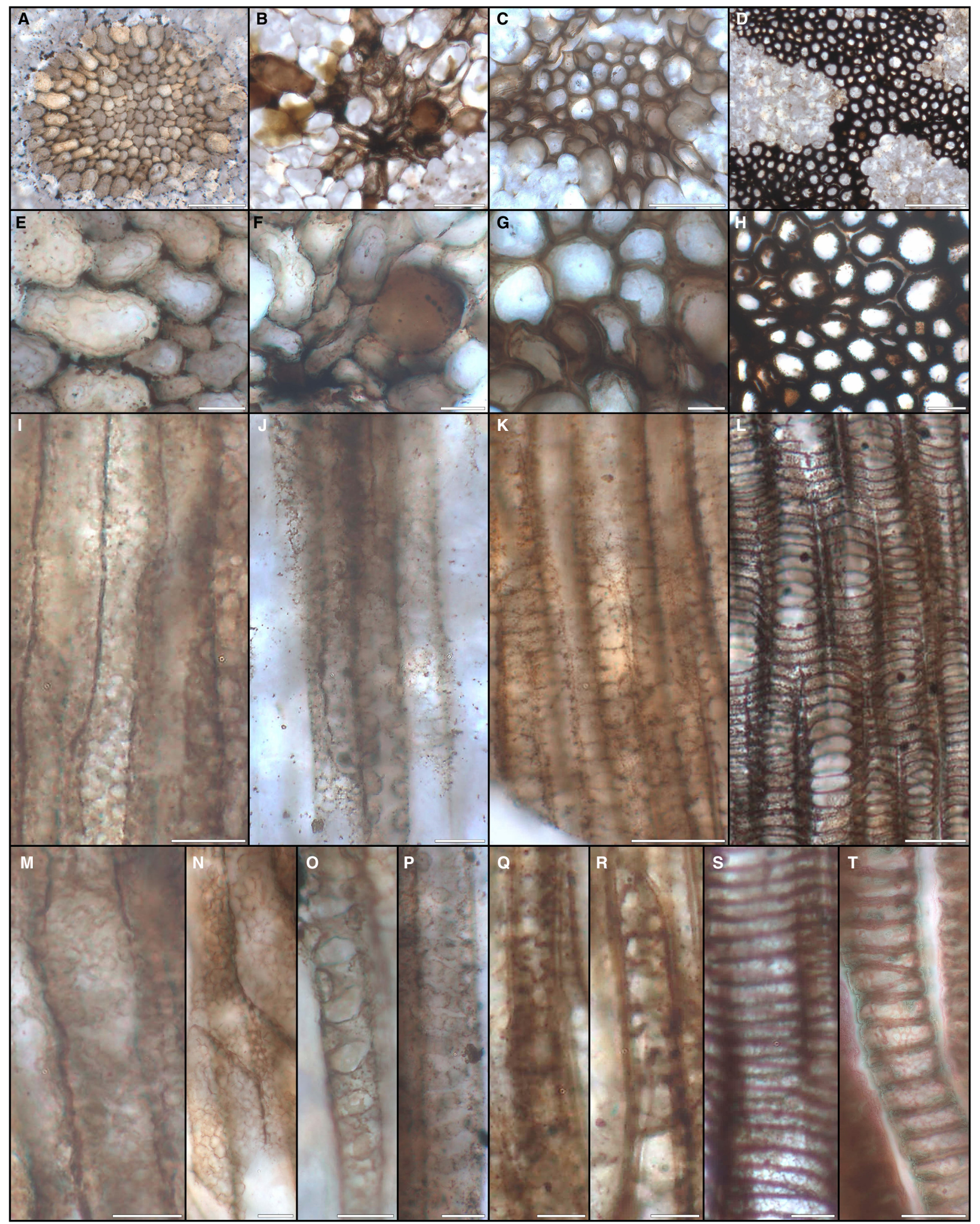

is most probably of secondary origin (Kearney et al. 2016). In another Rhynie chert plant, Nothia aphylla, for which decay resistance is accepted (Kenrick \& Crane 1997), water-conducting cells have no thickenings (Edwards 2003). However, the walls of the conducting cells of Nothia appear remarkably thicker than those of Aglaophyton and Rhynia (Kenrick \& Crane 1997). The walls of Horneophyton 
Fig. 1. Rhynie chert water-conducting cells observed from the historical collections of the Natural History Museum of Lille. A-H, transverse thin sections (TS). I-T, longitudinal thin sections (LS). A, conducting strand of Aglaophyton majus (TS, scale bar $=100 \mu$ m; MGLame-4); B, vascular strand of Rhynia gwynne-vaughanii (TS, scale bar $=100 \mu \mathrm{m}$; MGLame-9); C, vascular strand of Horneophyton lignieri (TS, scale bar $=100 \mu \mathrm{m}$; MGLame-18); D, vascular strand of Asteroxylon mackiei (TS, scale bar $=100 \mu \mathrm{m}$; MGLame-27); E, detail of water-conducting cells of $A$. majus (TS, scale bar $=20 \mu \mathrm{m}$; MGLame-4). F, Detail of S-type tracheids of $R$. gwynne-vaughanii (TS, scale bar $=20 \mu \mathrm{m}$; MGLame-9); G, detail of water-conducting cells of $H$. lignieri (TS, scale bar $=20 \mu \mathrm{m}$; MGLame-18); H, detail of tracheids of A. mackiei (TS, scale bar $=40 \mu \mathrm{m}$; MGLame-27); I, water-conducting cells of $A$. majus (LS, scale bar $=20 \mu \mathrm{m}$; MGLame-8); J, waterconducting cells of R. gwynne-vaughanii (LS, scale bar $=25 \mu \mathrm{m}$; MGLame-15); K, water-conducting cells of $H$. lignieri (LS, scale bar $=50 \mu \mathrm{m} ;$ MGLame-18); L, tracheids of A. mackiei (LS, scale bar = 50 $\mathrm{m}$; MGLame-29); M, N, detail of water-conducting cells of A. majus (LS, scale bar $=20 \mu \mathrm{m}$; MGLame-8); $\mathrm{O}, \mathrm{P}$, detail of water-conducting cells of $R$. gwynne-vaughanii (LS, scale bar $=20 \mu \mathrm{m}$; MGLame-15-16); Q, R, detail of water-conducting cells of H. lignieri (LS, scale bar $=25 \mu \mathrm{m}$; MGLame-18); S, T, detail of tracheids of A. mackiei (LS, scale bar $=20 \mu \mathrm{m}$; MGLame-29, MGLame-27). [Colour figure can be viewed at wileyonlinelibrary.com]

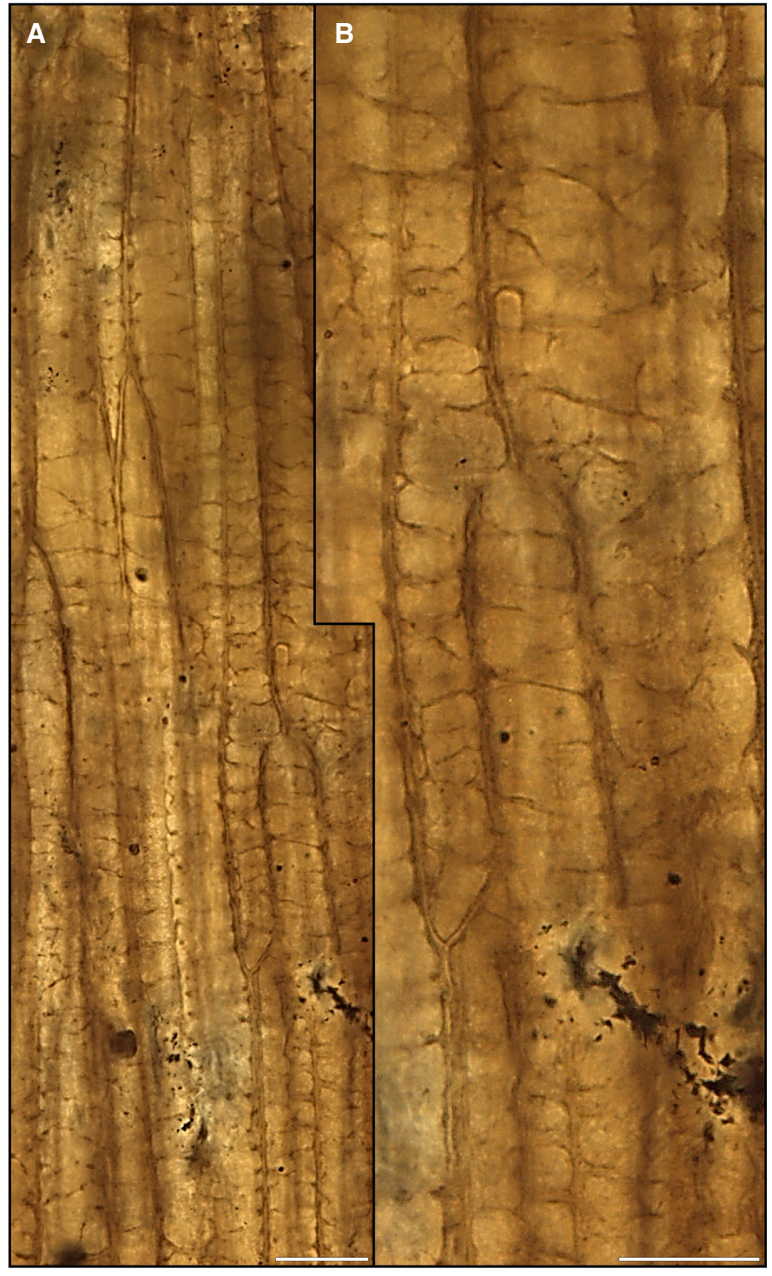

Fig. 2. Horneophyton water-conducting cells observed from the Rhynie chert collections of Munster University (Slide P 5012). A, general view of the Horneophyton specimen illustrated in Kerp (2017, fig. 1h); B, zoom view of A showing the structure of Horneophyton conducting tissues. Scale bar $=25 \mu \mathrm{m}$. Pictures courtesy of Hans Kerp. [Colour figure can be viewed at wileyon linelibrary.com]

water-conducting cells (Fig. 1G) are also thicker than those of Rhynia (compare Figure 1F with Fig. 1G), and much thicker than those of Aglaophyton (compare Figure 1E with Figure 1G). The thickness of the walls of Horneophyton conducting cells is indeed much closer to that of the conducting cells of
Asteroxylon (Fig. 1G, H). So, as for Asteroxylon, Horneophyton decay resistance was scored as extensive in our analysis, while that of Rhynia is scored as limited (character 16, Table S1).

Early polysporangiophytes mainly present waterconducting cells with annular or helical thickenings (Kenrick \& Crane 1991). These tracheid-like cells or tracheids are well known in paratracheophytes, as well as in zosterophylls or basal lycopods such as Asteroxylon or Baragwanathia (Kenrick \& Crane 1991; Kenrick et al. 1991a,b). The presence of this type of thickenings in Horneophyton has been described in several studies (Kidston \& Lang 1920a; Barghoorn \& Darrah 1938; Edwards 2004; Kerp 2017) and is again illustrated here (Fig. 1G, K). The thickenings are, however, irregular and less welldeveloped than in Asteroxylon (Fig. 1S, T), or even in Rhynia, where we see a banded appearance (Fig. 1O, $\mathrm{P})$. Nevertheless, because annular or helical thickenings, even if irregular, are obvious in Horneophyton, the character 'tracheid thickenings' was scored as present in our analysis (character 17, Table S1).

The results of our cladistic analysis contrast with the currently accepted fossil-based plant phylogeny (Fig. 4A) that presents two intermediate lineages between the bryophytes and tracheophytes. These lineages correspond to the Rhynie chert plants Horneophyton and Aglaophyton. This conception mainly derives from the presence of a columella in Horneophyton sporangium and of apparently uniform cell walls in Aglaophyton conducting cells. According to this model, tracheophytes include two sister clades, represented here by the Rhynie chert plants Rhynia (paratracheophytes, Fig. 3) and Asteroxylon (eutracheophytes, Fig. 3), the latter being sister to euphyllophytes, that is the plants with 'true leaves' or megaphylls, a lineage that includes almost all living vascular plants. Our results, however, suggest an alternative, and more parsimonious model for interpreting the basal relationships in land plant evolution (Fig. 4B), with Horneophyton (and allies) being sister to eutracheophytes instead of being the earliest, nonvascular polysporangiophyte. 

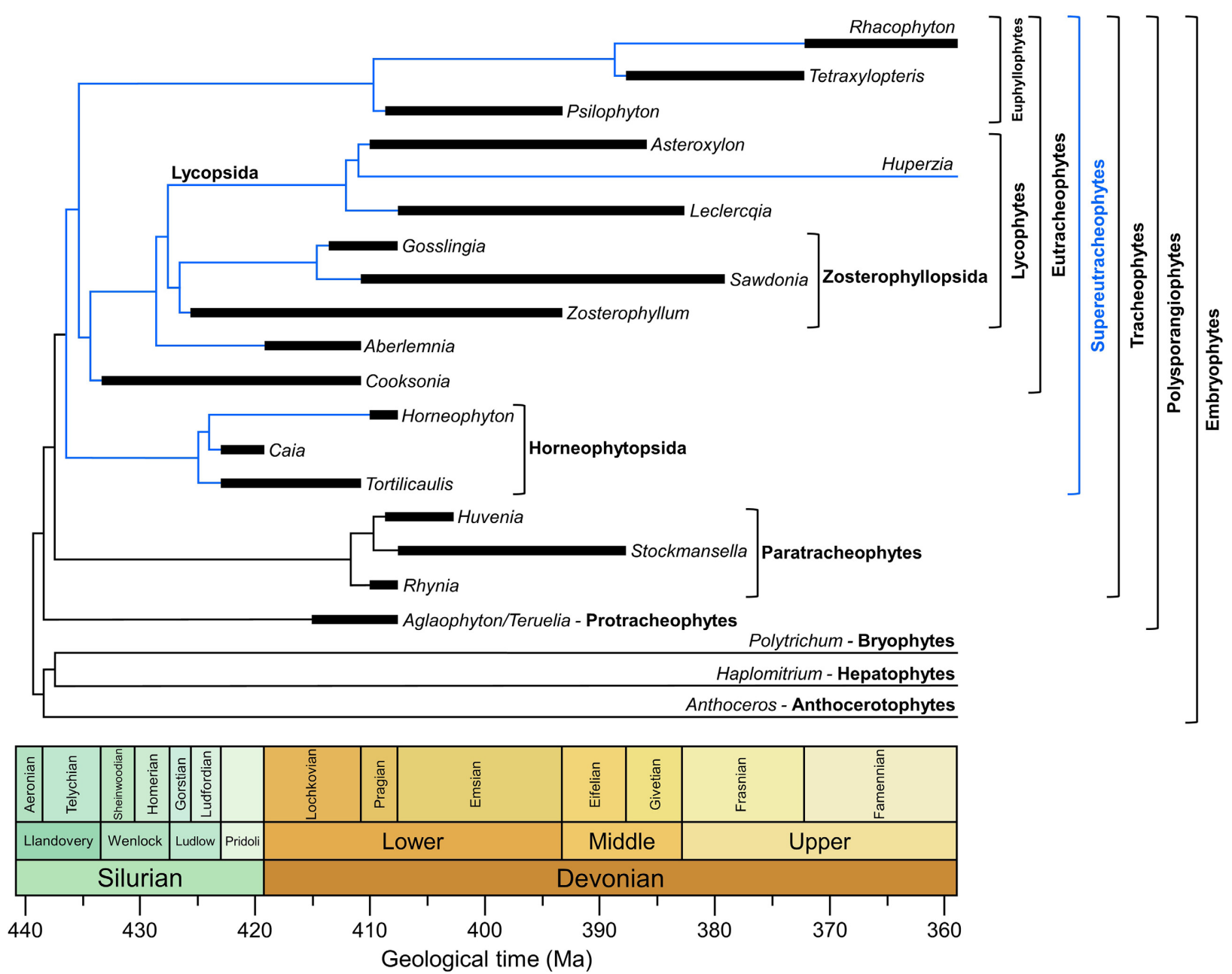

Fig. 3. Time-scaled phylogeny of earliest land plants. Major clades are in bold. Black boxes indicate the temporal distribution of involved taxa. Blue colour highlights the supereutracheophyte clade. See Material and Methods for details. [Colour figure can be viewed at wileyon linelibrary.com]

The acquisition of more efficient water-conducting cells was decisive during the terrestrialization process. The presence of vascular tissues is therefore a key synapomorphy for understanding polysporangiophyte evolution. Tracheids are defined in terms of form, function and biochemical composition (Niklas \& Smocovitis 1983), the latter character being the most difficult to assess in fossils. All the features identifying tracheid (secondary wall deposition, presence of lignin, pitting of wall) were presumably acquired sequentially; this is exemplified by the four plants illustrated here that document the initial steps of the process. In fossil plants, the presence of lignified conducting cells can only be assumed from the presence of a decay-resistant layer. This layer is evaluated from comparative morphology with extant plants. There are no direct unequivocal measures showing the presence of lignin neither for any Early Devonian tracheids nor for any early land plant.
However, the fossil record shows a great variety of conducting cells and not all of them possess a decay resistance nature. The best example is the S-type conducting cell. These cells, characteristics of paratracheophytes such as Sennicaulis, Rhynia or Huvenia and related plants, are elongate, with annular/helical thickenings, but with a very thin decay-resistant layer (Kenrick \& Crane 1991) in which the presence of lignin is still elusive (Boyce et al. 2003; Kearney et al. 2016). Interestingly, Aglaophyton water-conducting cells strongly resemble the morphology found in Rhynia or Huvenia conducting tissues (Remy \& Hass 1996; Kearney et al. 2016). This fact suggests, together with similarity observed between Aglaophyton and Rhynia central strands (see Fig. 1E, F), and the morphology of its reproductive structures (Kenrick \& Crane 1997; Cascales-Miñana \& Gerrienne 2017), that Aglaophyton might be included in the paratracheophytes, likely as its basalmost 


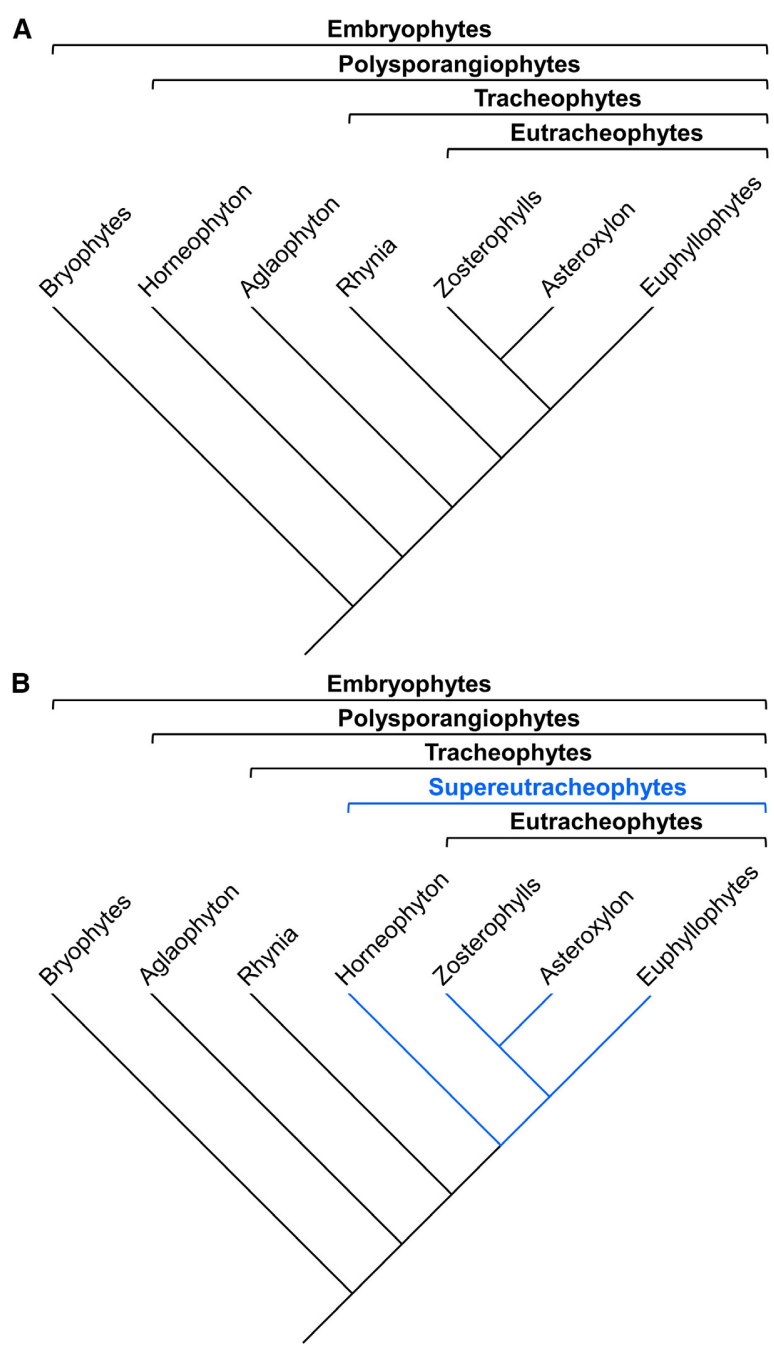

Fig. 4. Synthetic comparison of the basalmost evolutionary relationships among land plants. A, currently accepted, most parsimonious, plant phylogeny. Based on Kenrick (2000, fig. 1A); B, proposed cladistics for the early land plants. Blue colour highlights the supereutracheophyte clade. [Colour figure can be viewed at wileyonlinelibrary.com]

representative. This has already been discussed by Edwards (2004), who suggested that similarities in xylem elements between Aglaophyton and Rhynia would seem to narrow the differences between both plants.

The other key element in the currently accepted phylogenetic position of Horneophyton is the presence of columellate sporangia (Eggert 1974; El-Saadawy \& Lacey 1979). This character is considered a bryophyte-like trait, and it is the mean feature advocating for the basalmost position of Horneophyton within polysporangiophyte evolution (Kenrick 2000). However, columellate sporangium is neither a character of all bryophytes, nor present in bryophytes only. This type of sporangium is absent in liverworts, not present in all hornworts, and is characteristics of mosses only (Goffinet \& Shaw 2009). Importantly, the fossil record shows also columellate sporangia in several Carboniferous lycopsids, that is in basal eutracheophytes, such as Oxroadia (Alvin 1965) or the sigillarian plant Mezocarpon (Pigg 1983). This means that the character 'presence of a columella in the sporangium' might by homoplasious, which reinforces the position of Horneophyton as a sister lineage to eutracheophytes (Figs 2, 3B), and therefore, as a precursor of the living vascular plant biodiversity.

There is an important 'time gap' between the earliest evidence for land plants, provided by the midOrdovician dispersed spore fossil record (Rubinstein et al. 2010), and the earliest vascular plant evidence, which corresponds to mid-Silurian Cooksonia macroremains (Libertín et al. 2018). This gap could still be larger if we consider the recently suggested Morris et al.'s (2018) time-scale. New molecularbased results estimate indeed that land and vascular plants emerged during mid-Cambrian-Early Ordovician and Late Ordovician-Silurian time intervals, respectively (Morris et al. 2018). No fossil evidence confirms such intervals, but a series of small fossil plant remains have been recently discovered from the uppermost Ordovician (Salamon et al. 2018). No unequivocal evidence of tracheophytes is known before Silurian times. As shown in Figure 3, Cooksonia is the oldest tracheophyte, and importantly also, is the oldest and basalmost eutracheophyte, but it is not the most primitive vascular plant. Due to its exceptional anatomical preservation, the Rhynie chert plants provide unique knowledge about the earliest steps of polysporangiophyte evolution. This is the reason why they occupy key positions in many models of plant evolution, especially tracheophytes. This fact also goes with an underrepresentation and with an identification bias of basal tracheophytes, even more so if we take into account that many Early Devonian plants are known from compression fossils only, with no information about their vascular strand.

\section{Conclusions}

Herein, we have shown the water-conducting cells of four Lower Devonian plants from the Lagerstätte of Rhynie (Aberdeenshire, Scotland) present in the slide collections of the Natural History Museum of Lille (France). Those plants, namely the protracheophytes (considered non-vascular) Aglaophyton and Horneophyton, the paratracheophyte Rhynia and the eutracheophyte Asteroxylon, are key taxa in the earliest evolution of vascular plants. This work confirms previous descriptions and interpretations of the 
water-conducting cells of Aglaophyton, Rhynia and Asteroxylon, but emphasizes that Horneophyton has a particular type of tracheid characterized by narrow, irregular, annular and/or, possibly spiral wall thickenings, and hence that it cannot be considered nonvascular anymore. Indeed, our new phylogeny resolves Horneophyton within tracheophytes, but as sister to eutracheophytes in a larger clade called supereutracheophytes. Results further suggest that the horneophytophytes are more derived than the paratracheophytes. The Rhynie Chert plants lived some 20 million years after the earliest Silurian records for vascular plants. Although based on a group of coeval plants, many of them displaying ancestral characters, the alternative scenario we propose for the basalmost evolution of vascular plants suggests a sequential acquisition of the characters of water-conducting cells. This results in a more parsimonious model characterized by a progressive increase in the complexity of the conducting tissues.

Acknowledgements. - We thank Paul Kenrick (Natural History Museum of London, UK) for his helpful comments for discussion. We thank Jessie Cuvelier (CNRS, France) for technical assistance and Thierry Oudoire (Natural History Museum of Lille, France) for allowing the examination of specimens. We also thank Hans Kerp (Munster University, Germany) who very kindly helped us to illustrate this work and provided insightful comments on the Rhynie flora. K.L. acknowledges ANR M6fossil grant (ANR-15-CE31-0003-01). P.G. and P.S. are F.R.S-FNRS Senior Research Associates. This research was funded by the IRePSE (FED 4129, University of Lille).

\section{References}

Alvin, K.L. 1965: A new fertile lycopod from the Lower Carboniferous of Scotland. Palaeontology 8, 281-293.

Barghoorn, E.S. \& Darrah, W.C. 1938: Horneophyton, a necessary change of name for Hornea. Botanical Museum Leaflets, Harvard University 6, 142-144.

Bell, M.A. \& Lloyd, G.T. 2104: Strap: an R package for plotting phylogenies against stratigraphy and assessing their stratigraphic congruence. Palaeontology 58, 379-38.

Boyce, C.K., Cody, G.D., Fogel, M.L., Hazen, R.M., Alexander, C.M.O.D. \& Knoll, A.H. 2003: Chemical evidence for cell wall lignification and the evolution of tracheids in early Devonian plants. International Journal of Plant Sciences 164, 691-702.

Cascales-Miñana, B. \& Gerrienne, P. 2017: Teruelia diezii gen. et sp. nov.: an early polysporangiophyte from the Lower Devonian of the Iberian Peninsula. Palaeontology 60, 199-212.

Channing, A. 2017: A review of active hot-spring analogues of Rhynie: environments, habitats and ecosystems. Philosophical Transactions of the Royal Society B 373, 20160490.

Edwards, D.S. 1986: Aglaophyton major, a non-vascular landplant from the Devonian Rhynie Chert. Botanical Journal of the Linnean Society 93, 173-204.

Edwards, D. 2003: Xylem in early tracheophytes. Plant, Cell \& Environment 26, 57-72.

Edwards, D. 2004: Embryophytic sporophytes in the Rhynie and Windyfield cherts. Transactions of the Royal Society of Edinburgh 94, 397-410.

Edwards, D., Kenrick, P. \& Dolan, L. 2017: History and contemporary significance of the Rhynie cherts - our earliest preserved terrestrial ecosystem. Philosophical Transactions of the Royal Society B 373, 20160489.

Eggert, D.A. 1974: The sporangium of Horneophyton lignieri (Rhyniophytina). American Journal of Botany 61, 405-413.

El-Saadawy, W. \& Lacey, W.S. 1979: The sporangia of Horneophyton lignieri (Kidston and Lang) Barghoorn and Darrah. Review of Palaeobotany and Palynology 28, 137-144.

Goffinet, B. \& Shaw, J. 2009: Bryophyte Biology, 580 pp. Cambridge University Press, Cambridge.

Kearney, P., Kerp, H. \& Hass, H. 2016: Whole-plant regeneration via epidermal cells in the axis of the early Devonian Rhynie Chert plant Rhynia gwynne-vaughanii Kidston et Lang. International Journal of Plant Sciences 177, 539-550.

Kenrick, P. 2000: The relationships of vascular plants. Philosophical Transactions of the Royal Society B 355, 847-855.

Kenrick, P. \& Crane, P.R. 1991: Water-conducting cells in early fossil land plants: implications for the Early Evolution of Tracheophytes. Botanical Gazette 152, 335-336.

Kenrick, P. \& Crane, P.R. 1997: The Origin and Early Diversification of Land Plants. A Cladistic Study, 441 pp. Smithsonian Institution Press, Washington DC.

Kenrick, P. \& Edwards, D. 1988: The anatomy of Lower Devonian Gosslingia breconensis Heard based on pyritized axes, with some comments on the permineralization process. Botanical Journal of the Linnean Society 97, 95-123.

Kenrick, P., Edwards, D. \& Dales, R.C. 1991a: Novel ultrastructure in water-conducting cells of the Lower Devonian plant Sennicaulis hippocrepiformis. Palaeontology 34, 751-766.

Kenrick, P., Remy, W. \& Crane, P.R. 1991b: The structure of water-conducting cells in the enigmatic early land plants Stockmansella langii Fairon-Demaret, Huvenia kleui Hass et Remy and Sciadophyton sp. Remy et al. 1980. Argumenta Palaeobotanica 8, 179-191.

Kerp, H. 2017: Organs and tissues of Rhynie chert plants. Philosophical Transactions of the Royal Society B 373, 20160495.

Kidston, R. \& Lang, W.H. 1917: On Old Red Sandstone plants showing structure, from the Rhynie Chert Bed, Aberdeenshire. Part I. Rhynia gwynne-vaughani Kidston and Lang. Transactions of the Royal Society of Edinburgh 51, 761-784.

Kidston, R. \& Lang, W.H. 1920a: On Old Red Sandstone plants showing structure, from the Rhynie Chert Bed, Aberdeenshire. Part II. Additional notes on Rhynia gwynne-vaughani, Kidston and Lang; with descriptions of Rhynia major, n. sp., and Hornea lignieri, n. g., n. sp. Transactions of the Royal Society of Edinburgh 52, 603-627.

Kidston, R. \& Lang, W.H. 1920b: On old red sandstone plants showing structure, from the Rhynie Chert Bed, Aberdeenshire. Part III. Asteroxylon mackiei, Kidston and Lang. Transactions of the Royal Society of Edinburgh 52, 643-680.

Libertín, M., Kvaček, J., Bek, J., Žárský, V. \& Štorch, P. 2018: Sporophytes of polysporangiate land plants from the early Silurian period may have been photosynthetically autonomous. Nature Plants 4, 269-271.

Ligrone, R., Duckett, J.G. \& Renzaglia, K.S. 2012: Major transitions in the evolution of early land plants: a bryological perspective. Annals of Botany 109, 851-871.

Morris, J.L., Puttick, M.N., Clark, J.W., Edwards, D., Kernick, P., Pressel, S., Wellman, C.H., Yang, Z., Scheneider, H. \& Donoghue, P.C.J. 2018: The timescale of early land plant evolution. Proceedings of the National Academy of Sciences, USA 115, E2274-E2283.

Niklas, K.J. \& Smocovitis, V. 1983: Evidence for a conducting strand in early Silurian (Llandoverian) plants: implications for the origin of land plants. Paleobiology 9, 126-137.

Pigg, K.B. 1983: Morphology and reproductive biology of the Sigillarian Cone Mazocarpon. Botanical Gazette 144, 600-613.

Puttick, M.N., Morris, J.L., Williams, T.A., Cox, C.J., Edwards, D., Kenrick, P., Pressel, S., Wellman, C.H., Schneider, H., Pisani, D. \& Donoghue, P.C.J. 2018: The interrelationships of land plants and the nature of the ancestral Embryophyte. Current Biology 28, 733-745.

Remy, W. \& Hass, H. 1996: New information on gametophytes and sporophytes of Aglaophyton major and inferences about 
possible environmental adaptations. Review of Palaeobotany and Palynology 90, 175-193.

Roberts, A.W., Roberts, E.M. \& Haigler, C.H. 2012: Moss cell walls: structure and biosynthesis. Frontiers in Plant Science 3, 166.

Rubinstein, C.V., Gerrienne, P., de la Punte, G.S., Astini, R.A. \& Steemans, P. 2010: Early Middle Ordovician evidence for land plants in Argentina (eastern Gondwana). New Phytologist 188, 365-369.

Salamon, M.A., Gerrienne, P., Steemans, P., Gorzelak, P., Filipiak, P., Le Hérissé, A., Paris, F., Cascales-Miñana, B., Brachaniec, T., Misz-Kennan, M., Niedźwiedzki, R. \& Trela, W. 2018: Putative Late Ordovician land plants. New Phytologist 218, 13051309.

Wellman, C.H. 2006: Spore assemblages from the Lower Devonian 'Lower Old Red Sandstone' deposits of the Rhynie outlier, Scotland. Transactions of the Royal Society of Edinburgh Earth Sciences 97, 167-211.

Wellman, C.H. 2017: Palaeoecology and palaeophytogeography of the Rhynie chert plants: further evidence from integrated analysis of in situ and dispersed spores. Philosophical Transactions of the Royal Society B 373, 20160491.

Wellman, C.H., Kerp, H. \& Hass, H. 2004: Spores of the Rhynie chert plant Horneophyton lignieri (Kidston \& Lang) Barghoorn \& Darrah, 1938. Transactions of the Royal Society of Edinburgh Earth Sciences 94, 429-443.

\section{Supporting Information}

Additional supporting information may be found online in the Supporting Information section at the end of the article.

Data S1. Character matrix used in the phylogenetic analysis.

Table S1. List of characters and character states used for coding data matrix. Modifications from Kenrick and Crane [1] are in bold.

Appendix S1. Data matrix (Nexus format) of PAUP analysis.

Appendix S2. Tree file (Newick format) of strap analysis.

Appendix S3. Age file (R package paleotree format) of strap analysis. 